REINFORCEMENT OF CORE VALUES: A CASE STUDY AT A MEDIUMSIZED ELECTRONICS MANUFACTURING PLANT

By: Judith A. Johnson and Dianne H.B. Welsh

Johnson, J.A., \& Welsh, D.H.B. (1999). Reinforcement of core values: A case study at a medium-sized electronics manufacturing plant. Work Study, 48(1), 21-24.

Made available courtesy of EMERALD GROUP: $\underline{\text { http://www.emeraldinsight.com }}$

***Note: Figures may be missing from this format of the document

\title{
REINFORCEMENT OF CORE VALUES: \\ A CASE STUDY \\ AT A MEDIUM-SIZED ELECTRONICS \\ MANUFACTURING PLANT
}

\author{
JUDITH A. JOHNSON \\ Eastern Washington University \\ 668 N. Riverpoint Blvd. \\ Spokane, WA 99202-1660 \\ (509) 922-8610 Office \\ (509) 927-2767 Fax \\ DIANNE H. B. WELSH \\ Eastern Washington University \\ 668 N. Riverpoint Blvd., Ste. A \\ Spokane, WA 99202-1660 \\ (509) 358-2259 Office \\ (509) 358-2267 Fax \\ dwelsh@ewu.edu
}


Address correspondence to Professor Dianne Welsh, Department of Management, Eastern Washington University, 668 N. Riverpoint Blvd., Suite A, Spokane, WA 992021660

The authors would like to thank the participation of the many employees from our study site.

\section{REINFORCEMENT OF CORE VALUES: A CASE STUDY AT A MEDIUM-SIZED ELECTRONICS MANUFACTURING PLANT INTRODUCTION}

The culture at this company was to recognize that their employees were there most important asset, as stated in their core values, "people are our greatest resource." The company's core values also state that enthusiastic and committed people are key to our success, and will: “1.) Partner with employees to achieve professional growth through training, development and education, 2.) Provide and maintain a safe and pleasant working environment, 3.) Treat all employees fairly and consistently, 4.) Encourage participation through team building, open communication and mutual respect."

The company's culture has always been to offer excellent pay and benefits, an open door communication policy, but even more importantly to recognize their employees efforts on a group and individual basis. For years the company had offered financial rewards common in industry, such as: gain sharing, employee recognition programs, such as, employee of the month, and token gift giving, such as holiday gift certificates to all employees. They professed to manage by positive reinforcement. 
Saying thank you was encouraged for a job well done, as well as postings on all bulletin boards that praised employees for making projects a success, and recognition at quarterly review meetings attended by co-workers.

In the last year, the company had gone through many changes. The president that initiated and supported this participative culture and positive management style resigned, going to one of the competitors. The population of employees had doubled, going from 600 to over 1400. Long standing employees had ridden the tidal wave of growth and the demands for them to provide training and mentor new employees while maintaining their own jobs was overwhelming. The new employees were also under great pressure to hasten their learning curve in order to meet the production demands. Additionally, the overall corporate culture was different than the focal plant culture due to

the fact that the British headquarters of the company did not encourage a participative culture, but was more control oriented and authoritative in style. There were many changes in the top echelons of management, all having different ideas on how to manage and how to reward. The vision of the company remained clear while there was individual differences as to the means to attain their goals. The dynamic growth, the learning curve, and their commitment to quality were all leading to getting back to the basics. The company was ignoring the culture that had always worked for them, the company was ignoring the non-financial rewards; such as saying thank you for a job well done, and the message that employees extra efforts were appreciated.

\section{LITERATURE REVIEW}

Non-Financial Rewards 
The debate as to the most beneficial approach to motivating employees continues among both academicians and practitioners. As substantiated by the following experts, it has been found that the non-financial rewards have the most impact on employee satisfaction and commitment.

Money is not the best motivator or reward according to Bob Nelson, author of 1001 Ways to Reward Employees (1997). In studies dating back to the 1940's, employees consistently have ranked other items as being more important than salaries. As cited in the 1994 National Study of the Changing Workforce, open communication was ranked the highest in importance among workers, with salary being ranked sixteenth. Being appreciated for work well done and an interesting work environment were also mentioned. This is not to say that some employees are not motivated by money, but recognition should also be given because recognition isn't just for the person who performed well, but it is also a message to other employees about the type of performance that gets noticed. It creates role models and heroes that communicate the standards. However, it is important to remember that rewards are not effective unless adequate pay is in force. It is integral to the success of any plan (Welsh, 1993).

A recent survey conducted by Robert Half International showed "limited praise and recognition" was ranked as the primary reason why employees were leaving their jobs. This was listed ahead of compensation. Dr. Gerald Graham, professor of management at Wichita State University in Wichita, Kansas, also found that money was not the top motivator. His research found that instant recognition is the most powerful motivator, followed by a letter of praise written by a manager. He evaluated 65 
different incentives. Informal rewards can be both effective and cost-free. It can be as simple as sincere praise, says Jack Zigon, president of Zigon Performance Group (“Improving Worker Performance”, 1996.) This is especially true if the praise is given with specific information about what the employee is being rewarded for.

In a study conducted by Welsh, Luthans, and Sommer (1993)entitled, "Managing Russian Factory Workers: The Impact of U.S. - Based Behavioral and Participative Techniques", supports that employees put value on something meaningful to them, rather than being given money. Further, the contrasts due to the various cultural and geographical locations must be taken into consideration when structuring reward systems.

The study is important because it proves that no matter what the culture or geographic sphere being operated in, recognition and praise are effective motivators anywhere non-financial rewards (praise and recognition by supervisors) as well as low cost financial rewards (t-shirts, foodstuff) were found to significantly effect quality production. However, non-financial rewards had the most impact. Both types of rewards have been found to be effective in all types of facilities; manufacturing, hospitals, retail stores, and non-profit institutions. This is not to say that financial rewards are not effective. The point here is that most firms only consider financial rewards and forget the importance of non-financial rewards.

Financial Rewards

It has been strongly suggested that companies change both their culture and rewards at the same time, (Hawk, 1995). Culture refers to the way in which people work, who makes decisions, and how levels of trust and respect are developed. Rewards go 
beyond financial returns, and include all the things about work and working that people find rewarding, such as recognition, career development, feedback and meaningful work. This ties to other studies about the importance of culture.

In 1993, Incentive magazine did a survey on the most preferred employee incentives and found that 64 percent of companies continue to rely on cash as their biggest motivator. Merchandise and travel moved up to 53 percent and 52 percent, respectively (Brooks, 1994).

Rewards must be linked to measurable results (Briton \& Dunne, 1996). Incentive plans are powerful tools that can improve a company's results. Poorly implemented plans can negatively affect corporate performance and morale. Incentive plans should proved a visible link between business strategy, results and individual rewards. This gives each employee a personal stake in the successful implementation of the business strategy.

From an organization's perspective, incentive plans create a common employee focus on key areas of business performance. From an employee's perspective, incentive plans provide meaningful recognition of their sustained individual efforts and collective achievements. Incentive plans provide a means of delivering positive reinforcement in ways that are meaningful to employees and support business strategies. One drawback is that by delivering rewards after the fact, they do not establish a link between business strategy and the desired results.

\section{METHODOLOGY}

Site 
This study took place in medium sized city in the state of Washington, a city with a population of 250,000 . The entire county has a population of approximately 450,000 . The plant encompasses two manufacturing facilities that supply materials and services used in the manufacture and packaging of integrated circuits and in the production of infrared detectors and other electronic equipment. The company serves all of the world's largest semiconductor manufacturers, including AMD, Hewlet Packard, IBM, Intel, Motorola, National Semiconductor, Philps, Samsung, Texas Instruments, Toshiba, NEC, Fujitsu, Mitsubishi, Hitachi and SGS Thomson.

The division has earned a leadership position in the semiconductor and microelectronics market due, in part, to the resources and expertise of its 178 year old parent company, a $\$ 4.5$ billion industrial materials company headquartered in London, England. It presently oversees operations in more than 37 countries and employees approximately 10,000 people full-time. The company has grown from $\$ 34$ million in sales in 1983 to approximately $\$ 600$ million in 1996, a compound annual growth rate of more than 28 percent.

Two product groups are headquartered at the study site employing approximately 1,000 people. One consists of wafer fabrication materials, manufacturing sputtering targets, compound semiconductors, thermocouples, high-purity metals, sapphires and clean room outsourcing services. The second product group is the assembly products group, which consists of products such as die attach materials, discrete products, heat sinks, heat spreaders and slugs, seal lids and contract manufacturing. In response to increasing demand for thermal management products, the company has expanded its production operations by opening an 106,000 square foot manufacturing 
facility half hour from the main plant.

Sample

The main manufacturing facility, where our study took place, is located in an industrial park area. There are approximately 1400 employees, 700 full time and 700 temporary employees. Their education ranges from high school degrees to Ph.D.'s. Their ages range from eighteen year olds to over 65 years of age. The majority of the employees have been employed less than five years by the company. Approximately 20 percent have more than ten years of service. Most of the jobs are considered low skilled and requires on-the-job training. The remainder of the positions are professional, such as engineers, and scientists.

The study began by the employees completing a base line survey measuring the aspects of their jobs, description of their jobs and products, attitudes toward the company, and their supervisors. After the survey was administered two days of classes totaling 16 hours of instruction was completed. The classes were held on-site and were taught by an outside consultant, Dr. Dianne Welsh, who has done extensive training in the area of reward systems. Instruction included lectures, videos, case studies and research, and group exercises. Basic concepts taught included the definition of reward, different types of rewards, how to make reward programs work, goals of a successful employee reward programs, the importance of feedback, and how to implement reward on-the-job. The employees were divided into similar work groups and allowed time to devise a reward system plan that was deemed applicable in their area. These plans were then presented to

the class. Classes were limited in size to 16 individuals from the same department and/or 
job classification level. Levels, for example, were primarily composed of all leads, supervisors, mid-managers, and engineers.

\section{RESULTS}

Approximately six months after the instruction sessions were completed follow up meetings were conducted with the same six class groups by the consultant. A major point of discussion at these meetings was need for top management support. Due to the company culture, the plant general manager needed to have spoken to each group at the onset of the training sessions to reinforce that management support for the program. Also it would have been helpful to conduct the sessions beginning with top management team , then following with middle managers, supervisors and leads, respectively. The results of the meetings showed that the leads and supervisors were very excited about what they have learned and are actually utilizing reward systems on the production floor. Middle and top managers utilized the non-financial reward systems to a lesser extent. The one draw back is that the leads do not feel empowered to actually offer any rewards that are low cost. One point of discussion at these meetings was that supervisors would like to be able to offer not only no cost rewards but also low cost financial rewards. Additionally, the participants believed that it was necessary for each area have their own reward budget, and administer the system. The supervisors had actually drawn up these plans in the class for reward systems, but had not been allowed to use the low cost rewards because there was not budget attached. Agreement as to what level and dollar amount the company would support financial rewards needed to have been established before the 
study commenced. General lessons learned by the supervisors included to not reprimand for mistakes, but instead to help the employee find the best way to work through the problems, actively get their areas working as a team, and to take time to get to know each worker personally. The attendees also realized that they could not change the attitudes and beliefs of all employees concerning rewards. However the supervisors could still practice what they had learned and have successful operating reward systems.

\section{CONCLUSION}

In conclusion, this study showed to have significant effects in the ability of the leads and supervisors to better manage their work force through the use of positive reinforcement, such as praise and recognition. The majority of the leads had been in their positions for just a short period of time so they had limited managerial training and were particularly open to new ideas. Many had recently occupied the positions they were now overseeing. Therefore, this management tool was easy to incorporate and readily adaptable into their daily routine and improved their interactions with employees. Many of the mangers commented that the use of non-financial rewards improved moral and that positive reinforcement was contagious, it readily caught on quickly in their departments.

It is important to guarantee support from upper management from the very start, and to have the top manager begin all training session by stating his/her support for the program and its application. It is integral to have management utilize these nonfinancial rewards with their direct subordinates so that the flow of reinforcement makes a complete circle. It is helpful to take one work area at a time when teaching these 
methods. Start with some measure of their current satisfaction and commitment levels, conduct the two day instruction starting with the most senior management then progress down the management hierarchy to encompass the leads.

After a pre-determined period of time, usually eight to twelve weeks measure these criteria with a survey again. Compare the results against a like area that did not receive the training and follow-up on non-financial and low cost rewards. There should be a significant positive increase in job satisfaction and commitment among those employees who received the training. 


\section{REFERENCES}

Briton, P. \& Dunne, L., (July/August 1996). Employee incentives. CGA Magazine Online, p. 1-6.

Brooks, S. (1994, April). Noncash ways to compensate employees. HR Magazine, 39 (4), p. 38

Graham, G. (1996, July). Rewards that motivate. Personnel Journal, 75 (7), 65-69.

Half, R. (1996, July). Rewards that motivate. Personnel Journal, 75 (7) 65-69.

Hawk, E. (1995, April). Culture and rewards: A balancing act. Personnel Journal, 74 (4), 30-35.

Nelson, B. (1996, July). Rewards that motivate. Personnel Journal, 75 (7), 65-69.

Nelson, (1994). 1001 ways to reward employees. New York: Workman Publishing

Welsh D., Luthans F., \& Sommer, S. (1993). Managing Russian factory workers: The impact of U.S.-based behavioral and participative techniques. Academy of Management Journal, 36 (1), 58-79. 